
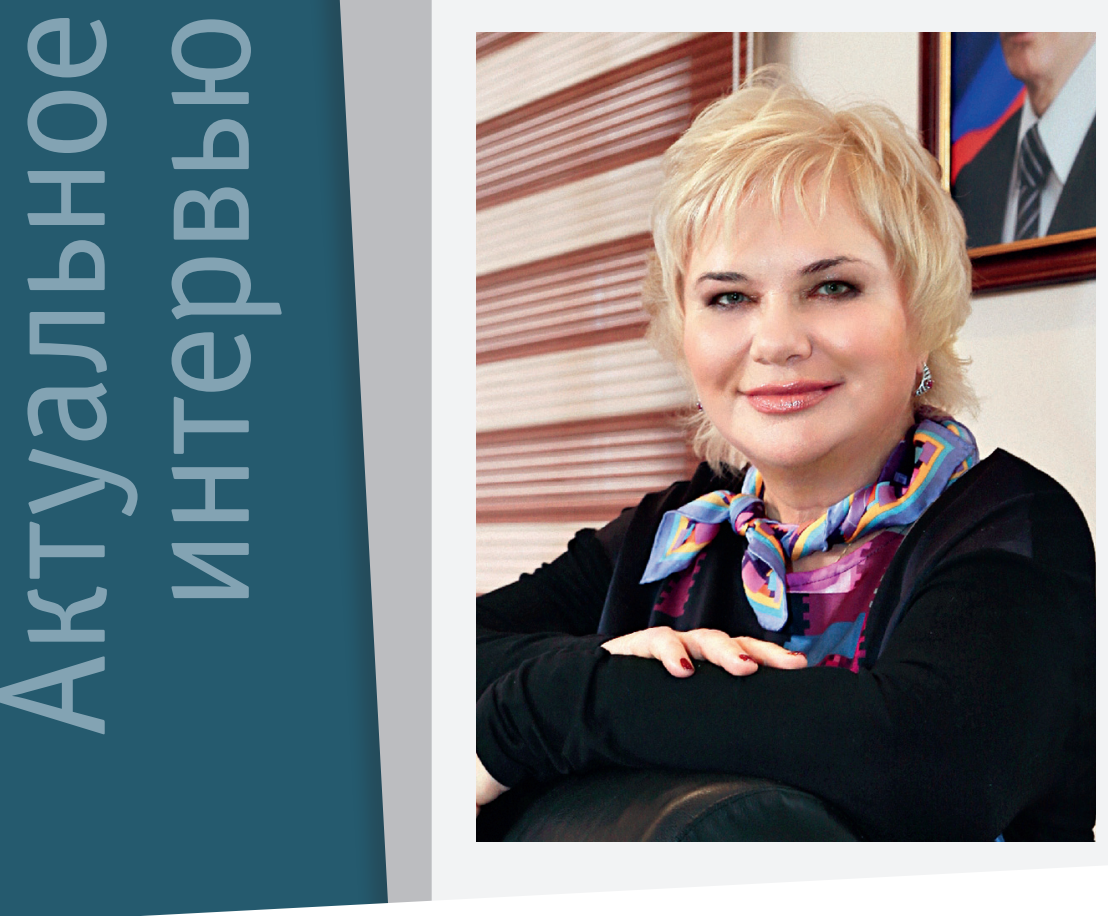

Страна села за парты. В новом учебном году в школы пошло 16,5 миллиона школьников, в вузы более четырех миллионов студентов.

Кто сегодня идет в инженеры? Чему сейчас учат будущих машиностроителей и управленцев и какие вызовы стоят перед технологическими вузами? Обо всем этом и не только мы побеседовали с ректором МГТУ «СТАНКИН» Еленой Георгиевной Катаевой.

\title{
ИНДУСТРИЯ БУДУЩЕГО: МИФ ИЛИ РЕАЛЬНОСТЬ?
}

- Как Вы оцениВаете итоги приемной кампании этого года, какие направления были наиболее популярны у абитуриентов в 2019 году, на какие специальности был самый большой конкурс?

- Приемную кампанию 2019 года без сомнения можно назвать успешной для МГТУ «СТАНКИН». Показателем этого служит увеличение количества поданных абитуриентами заявлений. В свою очередь, это привело к росту проходного и среднего балла поступающих, что позволило улучшить качество приема по всем направлениям подготовки. К нам пришли сильные ребята, и это очень радует.

Самыми популярными направлениями бакалавриата стали IT-направления: информатика и вычислительная техника, информационные системы и технологии, прикладная информатика и направления из укрупненной группы «Экономика и управление». Однако не менее популярными направлениями подготовки были «Автоматизация технологических процессов и производств» и «Мехатроника и робототехника». На этих направлениях отмечался большой конкурс - более 15-20 заявлений на место. Средний балл поступающих по этим направлениям доходил до 80 баллов, а средний балл всех поступивших в итоге составил 72,6 балла, что на 4,6 балла больше, чем в прошлом году.

Это является следствием того, что мотивированные на развитие своих компетенций школьники выбирают направления, связанные не только с информационными технологиями. Кадры для цифровой экономики - это не только программисты. Это в первую очередь те высококлассные специалисты, которые будут заниматься цифровизацией промышленности, разработкой и внедрением технологий, направленных на повышение производительности. Именно поэтому мы и наблюдаем рост конкурса. Повышается интерес к тем образовательным программам, в которых навыки программирования, решения сложных логических задач ориентированы на прикладные области, в частности, развитие киберфизических производственных систем. И если говорить об увеличении контрольных цифр приема, то это в первую очередь прикладная информатика.

В этом году впервые при поступлении в магистратуру интерес к «железным» направлениям превысил интерес к IT. Это является проявлением 
важной тенденции на рынке труда: ряд сегментов рынка труда IT-специалистов не воспринимает наличие магистерского диплома как условие для карьерного продвижения. В то же время для выпускников, закончивших бакалавриат в IT-области, становится необходимым развитие инженерных компетенций в прикладных областях, например, в машиностроении, мехатронике и робототехнике. В целом мы с удовлетворением отмечаем, что доля выпускников других вузов, поступающих в магистратуру МГТУ «СТАНКИН», составляет уже более одной трети.

- Какие специальности получат больше Всего бюджетных мест, изменилось ли их количество и какие новые специальности появятся В МГТУ "СТАНКИН»?

- По сравнению с приемом прошлого года в университете отмечен рост количества бюджетных мест. К примеру, если рассматривать только бакалавриат и специалитет, то прием на бюджетные места увеличился более чем на 50 бюджетных мест. По нашему мнению, все зависит от потребностей рынка труда через 5-10 лет. Университет пытается предугадать прослеживаемые тенденции в этом направлении и отталкивается от этого при подготовке заявки на выделение контрольных цифр приема на каждый год набора, чтобы вчерашние абитуриенты, а ныне студенты первого курса, по окончании своего обучения были востребованы.

Мы предполагаем, что новые специальности это специальности на стыке направлений подготовки. Мы уже сейчас пытаемся приблизиться к этому, и, например, у нас в рамках направления подготовки «Мехатроника и робототехника» реализуется профиль Медицинской робототехники, по которому в июне 2019 года состоялся первый выпуск. Такие «гибридные» направления мы планируем и дальше реализовывать и развивать в нашем университете.

- Какая мотивачия, на Ваш Взгляд, у ваших абитуриентов и студентов?

- МГТУ «СТАНКИН» является базовой площадкой Центров технологической поддержки образования (ЦТПО) города Москвы, а также имеет в своей структуре Федеральный центр технического творчества учащихся. Через нас проходит свыше 3000 школьников ежегодно. Имея такую мощную базу, мы можем видеть общую картину и отмечаем стабильно возрастающий интерес молодежи к инженерному творчеству и инженерной деятельности среди школьников. Год от года профориентационные мероприятия, начиная с «университетских суббот», различных научно-популярных лекций инженерной направленности и экскурсий на промышленные предприятия и заканчивая кружками по программированию и робототехнике, привлекают все больше участников. Также растет число и охват различных конкурсных мероприятий в этой сфере. Все это приводит к тому, что к нам приходит все больше и больше высоко мотивированных абитуриентов, которые хотят связать свою жизнь и профессию с инженерией, а не просто получить диплом «для галочки». Случайных людей у нас нет.

Своим абитуриентам мы рассказываем, что мир стоит на пороге новой промышленной революции. Мы шагаем в эру тотальной цифровизации инженерной деятельности, идем к «безлюдным» производствам, управлять которыми сможет только специалист с широким инженерным кругозором. Мы также объясняем, что управление станком в новой реальности - это уже не вращение рукоятки подачи, а выбор нужных настроек в мобильном приложении. В этой связи главная задача вуза не столько прививать студентам знания и навыки, востребованные в текущий момент, сколько готовить кадры на перспективу. Выпускник современного университета должен обладать большим объемом междисциплинарных знаний, быть готов работать в парадигме «Индустрии 4.0» и отвечать всем требованиям нового технологического уклада. Такие перспективы значительно повышают мотивацию студентов не только активно осваивать новые знания, но и активно искать возможности их применения в науке и инженерной деятельности.

- Насколько приВлекательны для Вас абитуриенты из регионов, хватает ли мест В общежитиях для иногородних студентов?

- Наш Университет не только сохраняет, но и наращивает привлекательность для сильных выпускников региональных школ. Доля студентов 1 курса, имеющих высокие баллы ЕГЭ, принятых с общежитием, впервые приблизилась к 60\%. Это говорит не только о привлекательности московского образования как такового, но и росте интереса именно к инженерному образованию. С другой стороны, высокая доля иногородних абитуриентов в приеме делает критически важным фактором успеха приемной кампании наличие общежития. Именно в общежитиях университет стал испытывать высокую потребность. Так, в этом году в МГТУ «СТАНКИН» было подано рекордное количество заявлений - 14778 на 1400 бюджетных мест, это максимальное количество за последние несколько лет. С каждым годом все больше увеличивается интерес к МГТУ «СТАНКИН» у иногородних абитуриентов, так как большая часть производства 
сосредоточена именно там, в регионах, и многие студенты и их родители, а также непосредственные работодатели заинтересованы в их возвращении обратно. В рамках особой квоты было выделено 88 мест, где по окончании приема заявлений было подано 126. Но не все воспользовались данным преимуществом, были даже те, кто поступал и по общему конкурсу.

- Вы обучаете не только студентов, но повышаете кВалификацию уже работающих специалистов? Насколько это Востребовано?

- Очень востребовано. Мы сегодня можем подготовить любую программу под конкретную компанию с обучением как на территории университета, так и на территории заказчика. Высокое качество дополнительных профессиональных программ МГТУ «СТАНКИН» подтверждается тем, что университет в течение ряда лет являлся победителем Президентской программы повышения квалификации инженерных кадров, автором лучшей образовательной ведомственной целевой программы Минобрнауки России «Повышение квалификации инженерно-технических кадров на 2015-2016 годы». За 2018 год мы обучили персонал из почти 50-ти компаний, в том числе таких предприятий, как «Энергомаш», «Тульский оружейный завод», завод «Купол» и др.

В настоящее время МГТУ «СТАНКИН» - исполнитель контракта по проекту «Организационнотехническое и экспертно-аналитическое сопровождение реализации ведомственной целевой программы «Развитие интегрированной системы обеспечения высококвалифицированными кадрами организаций оборонно-промышленного комплекса Российской Федерации в 2016-2020 годах».

В этом году нами были разработаны различные программы повышения компетенций руководящего и управляющего состава предприятий. Все программы повышения квалификации МГТУ «СТАНКИН» имеют адаптивный формат. Теперь у слушателей есть возможность пройти индивидуальное обучение (1-2 человека) и стажировку в малой группе (3-5 человек) под задачу конкретного предприятия, нет уже необходимости ожидать формирования большой группы.

\section{- Какие большие Вызовы сегодня решает «СТАНКИН»?}

- Ядром нашей деятельности является направление «А» Стратегии НТР РФ: переход к передовым цифровым, интеллектуальным производственным технологиям, роботизированным системам, новым материалам и способам конструирования; создание систем обработки больших объемов данных, машинного обучения и искусственного интеллекта.

Данное направление соответствует большому вызову «исчерпание возможностей экономического роста России, основанного на экстенсивной эксплуатации сырьевых ресурсов, на фоне формирования цифровой экономики и появления ограниченной группы стран-лидеров, обладающих новыми производственными технологиями», а также «угрозы национальной (технологической) безопасности».

Полноценное обеспечение реализации Стратегии НТР по пункту «А» требует значительной концентрации ресурсов на критическом для технологической безопасности страны направлении - современном станкостроении, фактически, воссоздании профильного отраслевого НИИ, которым во времена СССР являлся ЭНИМС.

Чтобы восполнить эту утрату, наш университет планирует сформировать на базе Государственного инжинирингового центра МГТУ «СТАНКИН» федеральный центр коллективного пользования. Он объединит экспертно-аналитическую, научноисследовательскую, опытно-конструкторскую и инжиниринговую функции, а также функции цифрового опытного производства в области развития высокотехнологичного импортонезависимого машиностроения и станкостроения. Первой задачей формируемой структуры должен стать комплексный анализ технологического уровня развития, степени импортозависимости и потребности в НИОКР предприятий машиностроения.

Ответ на большие вызовы также соответствует отраслевому запросу на реализацию проектов в области разработки цифровых производств, создания цифровых двойников производственных систем, гибких производственных ячеек и пр. В прошлом году нами была запущена профильная программа подготовки магистров (Инжиниринг производственных систем), реализуется несколько передовых программ повышения квалификации для сотрудников предприятий, составленных с учетом опыта университета Аахена. Данное направление станет ключевым «нишевым» направлением развития хоздоговорной деятельности университета, приносящей внебюджетные доходы. Кроме того, в логике тренда цифровизации отраслей экономики сейчас переконфигурируется деятельность подразделений университета, обладающих IT-компетенциями и опытом работы с большими данными. Такая диверсификация в медицину, сельское хозяйство, градостроительство активно прорабатывается университетом, есть хорошие результаты, в том числе в работах, реализуемых совместно с Медико-стоматологическим университетом им. А.И. Евдокимова. 


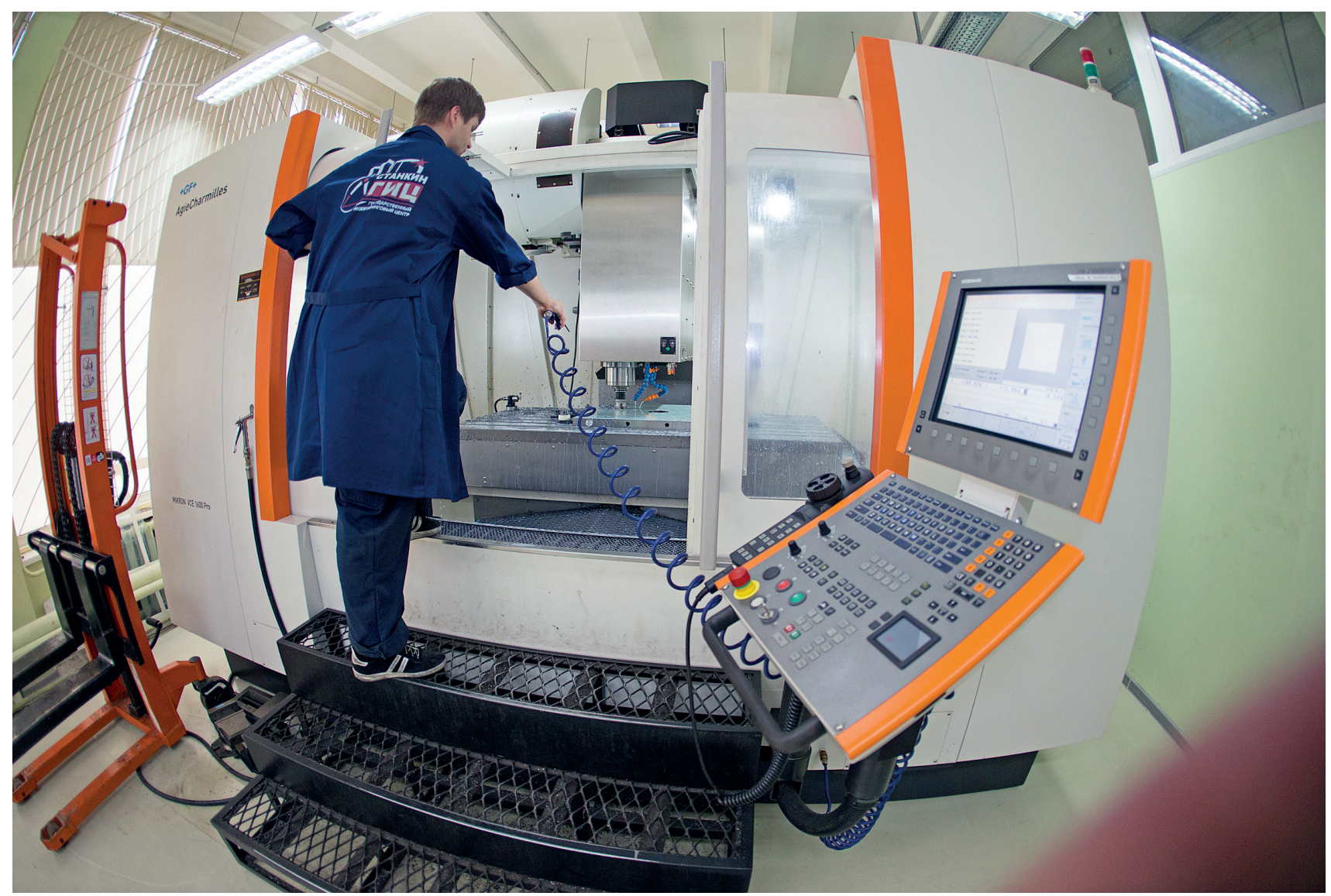

- "СТАНКИН» Выступил с инициатиВой создания ЕВразийского инжинирингоВого чентра по станкостроению и Ассоциации «Цифровые инновации В машиностроении». Какова их иель?

- В 2016 году решением Межправсовета государств - членов ЕАЭС в соответствии с Основными направлениями промышленного сотрудничества была утверждена Концепция создания Евразийского инжинирингового центра по станкостроению (ЕИЦ). В марте 2019 года Центр был зарегистрирован с учредителями от российской, армянской, белорусской и кыргызской сторон и в настоящее время функционирует на базе МГТУ «СТАНКИН» в Москве. В ближайшее время в состав учредителей войдут и представители Казахстана.

По нашему мнению, Евразийский инжиниринговый центр по станкостроению должен стать действенным инструментом координации промышленных политик государств - членов Союза. ЕИЦ ориентирован на решение четырех базовых задач, среди которых координация и интеграция усилий государств - членов ЕАЭС в области долгосрочного развития станкостроения; определение и сопровождение приоритетных проектов по созданию востребованных образцов технологического оборудования и ПО для рынка стран ЕАЭС; реализация функций по техническому регу- лированию, межгосударственной стандартизации, совершенствованию системы подтверждения соответствия; решение задачи подготовки и повышения квалификации отраслевых кадров по всему жизненному циклу современных промышленных предприятий с учетом вызовов цифровой трансформации отраслей.

Для достижения этих целей нужно сформировать условия, при которых Евразийский инжиниринговый центр был бы вовлечен в определяющие отраслевые процессы в станкостроении стран ЕАЭС, в частности, привлечение ЕАЭС к разработке стратегии станкоинструментальной промышленности Евразийского экономического союза на долгосрочную перспективу; закрепление в национальном законодательстве положений о независимом технологическом аудите инвестиционных проектов; инициирование проведения мониторинга потребностей промышленности стран ЕАЭС в кадрах и компетенциях в станкоинструментальной области и в сфере развития современного цифрового производства; закрепление в национальном законодательстве стран ЕАЭС норм, регламентирующих, что подготовка заключений о наличии производства аналогов ввозимого станкоинструментального оборудования на территории ЕАЭС производится ЕИЦ. 


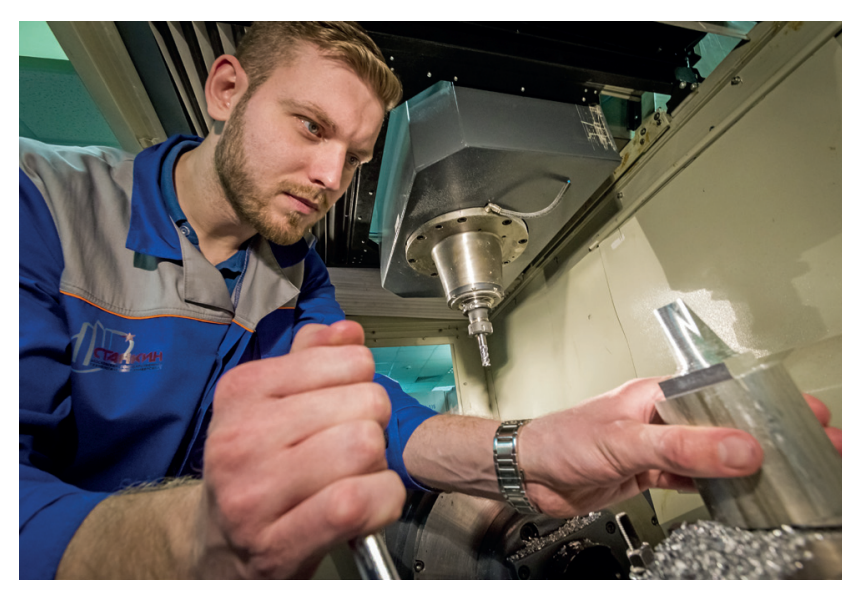

В конце 2018 году в МГТУ «СТАНКИН» состоялось Учредительное собрание Ассоциации «Цифровые инновации в машиностроении». Учредителями Ассоциации стали высокотехнологичные предприятия машиностроения, флагманы российского IT-рынка, ведущие образовательные и научные организации: «АСКОН», «1С», «ЦИФРА», «Балтийская Промышленная Компания», «НПО Энергомаш», «КЭМЗ», МГТУ «СТАНКИН», СанктПетербургский политехнический университет Петра Великого, Уральский федеральный университет, «ВНИИИНСТРУМЕНТ», Национальный институт авиационных технологий и др.

Цель Ассоциации - консолидация общих усилий для динамичного развития и обеспечения конкурентоспособности отечественного машиностроения на основе цифровых инноваций и гармоничного взаимодействия с ведущими отраслями промышленности в условиях формирования национальной цифровой экономики и применения принципов «Индустрии 4.0».

По нашему замыслу, именно данная Ассоциация должна стать ключевым механизмом выработки приоритетов цифровой трансформации машиностроения и экспертной площадкой, реализующей функции «коллективного заказчика».

\section{- Расскажите о международном сотрудниче- стВе МГТУ «СТАНКИН». \\ - Стратегические цели международного раз-} вития заключаются в том, чтобы обеспечить позиционирование МГТУ «СТАНКИН» в качестве лидера процесса интеграции российской высшей технологической школы в области цифрового инжиниринга производственных систем в международное техническое образовательное пространство, а также в качестве активного участника процессов экспорта российского образования и равноправного партнера для наиболее престижных зарубежных технических университетов, организаций, исследовательских консорциумов, зарубежных компаний и корпораций.
Университет одним из первых начал научнообразовательное сотрудничество с Сирией и вошел в качестве участника в структуру сформированной Минпромторгом России Дорожной карты по развитию торгово-промышленного сотрудничества между Российской Федерацией и Сирийской Арабской Республикой на период 2018-2020 годов.

Сегодня подписаны соглашения с двумя вузами Сирии, готовится к подписанию в сентябре-октябре еще одно соглашение. На основе ранее подписанного соглашения о научном и академическом сотрудничестве между МГТУ «СТАНКИН» и университетом Аль-Баас (Сирия, г. Хомс) открыт российско-сирийский научно-исследовательский учебный центр. Реализуются программы повышения квалификации ППС, готовится к реализации программа двойных дипломов, в 2019-2020 учебном году МГТУ «СТАНКИН» готовится провести на территории Сирии Международную многопрофильную олимпиаду «МОСТ» для школьников и студентов, одной из целей которой является продвижение русского языка в Сирии.

Кстати, участие в нашей олимпиаде «МОСТ» уже не первый год вызывает огромный интерес в странах СНГ. В 2019 году более 3000 школьников старших классов из Узбекистана, Казахстана, Таджикистана приняли участие в олимпиаде. Победители олимпиады имеют определенные преимущества при поступлении в «СТАНКИН».

Развивается сотрудничество с Шанхайским университетом науки и технологий. В настоящее время восемь китайских специалистов проходят научную 3-недельную стажировку в МГТУ «СТАНКИН».

Успешно сотрудничаем по образовательной линии с Узбекистаном. В этом году более 30 выпускников бакалавриата партнерских вузов из Узбекистана поступили в «СТАНКИН» в магистратуру на программы двойных дипломов, которых сегодня четыре, а со следующего года количество таких программ будет еще больше. Для каждой из таких программ мы не только с большой тщательностью подбираем вуз - партнер в Узбекистане, но и ищем

Московский государственный технологический университет «СТАНКИН» (МГТУ «СТАНКИН») - российский машиностроительный вуз, один из девяти системообразующих университетов в России. Основан в 1930 году как Московский станкоинструментальный институт. В состав вуза входят четыре института: машиностроения и инжиниринга (ИМИ), информационных систем и технологий (ИИСТ), автоматизации и робототехники (ИАР), экономики и технологического менеджмента (ИЭТМ). В 2018 году по результатам исследований журнала Forbes МГТУ «СТАНКИН» занял 15-е место в рейтинге российских вузов. 
соответствующих индустриальных партнеров для формирования баз практик и перспектив трудоустройства наших выпускников.

- Есть ли результаты сотрудничества с европейскими университетами?

- На новый уровень выведено сотрудничество с Высшей технической школой (ВТШ) Цюриха. Директор Института станков и технологий ВТШ профессор Конрад Вегенер, Почетный доктор МГТУ «СТАНКИН», прочитал цикл лекций для студентов и преподавателей. Под его руководством нашим выпускником Михаилом Клюевым защищена диссертация на соискание степени Dr.Sc.

Активно работаем с Техническим университетом Граца (Австрия). Директор Института производственных технологий ТУ Граца профессор Ф. Хаас весной прочитал в «СТАНКИН» лекции для студентов. В сентябре в качестве приглашенного профессора в ТУ Грац едет профессор нашего университета Андрей Кутин.

Достигнута договоренность о продолжении организации стажировок профессорско-преподавательского состава и практик обучающихся по программе обмена Erasmus+ в Зеленогурском университете (Польша). Сейчас в МГТУ «СТАНКИН» по этому направлению обучаются представители из Польши.

Заключено соглашение с Миланским политехническим университетом. Уже стало традиционным прохождение нашими студентами в Италии научной стажировки. Осенью мы направляем очередную группу.

Дополнительно можно отметить, что в рамках квоты на обучение иностранных граждан, предоставляемой Правительством РФ, по заявкам на обучение в наш университет в 2019 году приедут учиться ребята из Албании, Сербии, Словакии.

МГТУ «СТАНКИН» имеет несколько десятков действующих договоров о сотрудничестве с зарубежными партнерами в научной и образовательной сферах. В прошедшем учебном году у нас обучались ребята из 58 стран, уже сегодня по количеству поданных заявок мы видим, что количество стран, из кото-

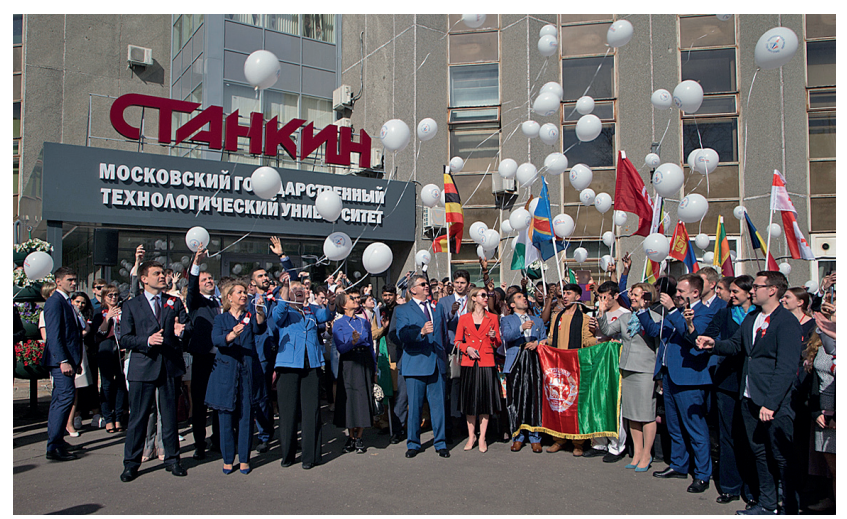

рых приедут на обучение к нам студенты, превысит цифру 60. Мы ожидаем 62-63 страны, что определяет вектор нашего развития.

На этот учебный год нами подготовлена программа развития международного сотрудничества и соответствующая дорожная карта. В планах проведение Международной конференции «Передовые производственные технологии» (АСТМ2020), посвященной 90-летию МГТУ «СТАНКИН», которая состоится в сентябре 2020 года. В работе конференции уже выразили желание участвовать зарубежные и отечественные ученые мирового уровня. Также планируется разработка магистерской образовательной программы «Киберфизические технологии» на английском языке для обучения иностранных и российских студентов. Кроме того, намечено выполнение работ по технологическому аудиту машиностроительных предприятий Кубы и значительное увеличение количества существующих совместных образовательных программ с зарубежными университетами.

\section{- Перед началом чемпионата мира} WORLDSKILLS в Казани пояВились многочисленные статьи и интервью о деградации Высшего образования и рождении нового подхода к процессу обучения, основанного на формировании системы навыков. Что Вы думаете об этом?

- Повышение престижа рабочих профессий и развитие профессионального образования на основе лучших практик профессионального мастерства, несомненно, важно для развития и построения нового общества, основанного на знаниях. Однако, необходимость анализа различных по природе процессов динамичной трансформации общества и техносферы предполагает наличие у специалиста - создателя новой техники и технологий глубоких фундаментальных знаний в различных областях науки. А чтобы не «изобретать велосипед», необходимо еще и знание истории и философии развития техники, теории машин и механизмов, системного анализа, инструментальных методов математического и компьютерного моделирования и многого другого, определяющего базис саморазвития молодого человека как специалиста и гражданина. И именно университетское образование дает возможность построить фундамент для получения новых знаний, соответствующих требованиям этого стремительно меняющегося общества. Поэтому высшее образование, обеспечивающее выпуск творцов будущего будет существовать всегда. Изменяется лишь форма передачи знаний. Поэтому, индустрия будущего, это - реальность, это завтра, рождающееся сегодня!

Интервъю подготовила Галина Соколвяк 